\title{
Features and Advantages of Using Websites in Teaching Mathematics (Interactive Educational Platform UCHI.ru)
}

\author{
Elvira G. Sabirova ${ }^{1 *}$, Tatyana V. Fedorova ${ }^{2}$, Natalya N. Sandalova ${ }^{3}$ \\ ${ }^{1}$ Kazan (Volga region) Federal University, Kazan, RUSSIA \\ 2 Samara State University of Social Sciences and Education, Samara, RUSSIA \\ ${ }^{3}$ Bashkir State Pedagogical University named after M. Akmulla, Ufa, RUSSIA
}

Received 11 October 2018 - Revised 18 February 2019 - Accepted 2 March 2019

\begin{abstract}
The number of electronic educational resources is multiplying day by day. Though such resources can be used in teaching children, teachers are not aware of their effectiveness thus far. So as to include websites in educational process purposefully and methodologically profoundly, it is important for the teacher to have cognizance of educational tasks that can be solved with the help of electronic resources, methodological functions they perform, and types of training activities they support and initiate. The paper is aimed to reveal the effectiveness of the interactive educational platform UCHI.ru while teaching math to primary school students. The leading methods applied in the research are as follows: testing, observation and analysis of educational process aimed to teach Mathematics to children aged between eight and nine through the use of UCHI.ru interactive educational platform to specify the dynamics of mathematical skills development in primary school students. The paper proves the validity of primary school students' mathematical training using UCHI.ru interactive educational platform; reveals features in teaching Mathematics to children aged 8-9 with the use of an educational website; identifies possible problem areas in teaching Mathematics using UCHI.ru interactive educational platform. UCHI.ru interactive educational platform, proposed in the paper, improves learners' motivation, facilitates their search competence formation and identifies gaps in basic knowledge of "Mathematics" as a subject for each student in class. UCHI.ru interactive educational platform can be employed by primary school teachers as supplementary didactic material.
\end{abstract}

Keywords: educational websites, interactive educational platforms, primary school students' training, teaching math to primary school students, mathematical skills

\section{INTRODUCTION}

Introduction of technologies related to the global Internet network in the educational process is becoming increasingly important at present (Galushkin, 2015; Kalugina \& Tarasevich, 2018; Rudenko et al., 2015; Petrovskaya et al., 2016; Vasbieva et al., 2018). These technologies are believed to enhance educational results; and such technologies as educational websites help master learning material without gaps. Learning motivation is growing noticeably (Lubnina et al., 2016). However, most primary school teachers in Russian schools have no idea about possible ways of using educational websites in teaching math. Teachers do not have enough information about the effectiveness of websites in educational process (Dmitrieva et al., 2015; Faleeva et al., 2017; Filatov et al., 2018; Firsova et al., 2018; Lubimova \& Sabanaev, 2014; Oborsky et al., 2018; Shcherbakov et al., 2017; Zaitseva et al., 2017, 2018).

(c) 2019 by the authors; licensee Modestum Ltd., UK. This article is an open access article distributed under the terms and conditions of the Creative Commons Attribution License (http://creativecommons.org/licenses/by/4.0/). \sabirovaelli@mail.ru (*Correspondence) $\square$ tatiana.fedorova2013@yandex.ru 


\section{Contribution of this paper to the literature}

- Features of teaching Mathematics to children aged between eight and nine with the use of UCHI.ru interactive educational platform has been specified: integration of supplementary interactive assignments into the educational process and extra-curricular activities.

- Probable problem areas in teaching mathematics using websites have been identified. These areas concern two aspects: content and technological levels of UCHI.ru interactive educational platform.

- The effectiveness of UCHI.ru interactive educational platform aimed to form mathematical skills in primary school students due to supplementary interactive assignments performance has been proved.

$89 \%$ of children use the Internet in Russia daily. 37\% of them surf the Internet for 3 - 8 hours on week days, and $47 \%$ on weekends (Kvon et al., 2017, 2018; Pyankova \& Matviyuk, 2014). Mobile Internet is twice as much popular with children as with their teachers and parents. Most children use the Internet to find interesting information. There is a real opportunity to teach children math using educational websites.

All educational websites for children have a common substance: desire to make learning and cognition more interesting, understandable and interactive. UCHI.ru interactive educational platform was chosen for the research as it met specified criteria: website rating; convenience of the site interface for primary school students' work; individual educational route for a primary school student; opportunity for independent selection of educational activity mode; free educational services.

In foreign pedagogical science, there is noted profound range of studies on the problem of teaching with websites. In domestic pedagogical literature this problem is studied insufficiently.

Modern educational web-resources are divided into the following groups: web-sites of educational institutions; web projects that implement educational process remotely; web sites that disseminate educational information; web sites for scientific research; web-sites of information-reference character; websites of competitive Internet projects; web-sites of educational-methodical associations; educational communities in social networks; educational web services (Griban \& Griban, 2015).

We arranged teaching of mathematics for children aged 8-9 years using UCHI.ru interactive educational platform at lessons and extra-curricular activities. We believe that age and individual characteristics should be considered while arranging the work: general outlook of the child necessary to present the content of a mathematical task; formation of mathematical concepts in child (e.g. names of shapes); formation of specific mathematical operations in child to solve tasks (e.g. count-down); solution algorithms formation in child (e.g., general methods of tasks solution); creating a "situation of success" for the child (Sabirova \& Zakirova, 2016).

The goal of the research is to prove the validity of mathematical skills formation in primary schoolchildren through the interactive educational platform UCHI.ru.

The objectives of the research are:

1) To identify features specific for teaching mathematics applying UCHI.ru interactive educational platform;

2) To determine problem areas in arranging teaching mathematics applying UCHI.ru interactive educational platform (analyses of teachers' and parents' questionnaires).

\section{LITERATURE REVIEW}

A high level of training through educational websites application is pointed out in foreign pedagogical science.

Application of information technologies in education is examined in the study of (Eileen Scanlon, 2014). It investigates the influence of digital epoch on scientists' work; the relationship between research and learning applying information technology is studied. Researchers assume that the mode of cognition process has changed. The paper investigates two areas: conducting research (in particular, activities related to publication and dissemination of research results) and training. The links between these two activities are studied in terms of new training technology reflected in academic practice both for teaching and research.

One of such teaching technologies is online education. Nowadays, there is paid much attention to development and research in this field. A large number of authors consider websites application for different participants in the educational process: learning through the Internet is regarded by Castaño-Muñoz, Duart, and Sancho-Vinuesa, 2014); they analyze the impact of interactive training on the quality of training. Scientists believe that mixed learning is more effective than full-time training. Research results show that the study of educational material on the Internet is useful only when it occurs in an interactive form. About mixed learning is written in the research of Wang (2017). Researchers tell that problem oriented online education is in the base of effective mixed learning, and especially integration of online and classroom education helps to achieve higher results in process of teaching. Researchers 
proved the advance in self-estimation of students, their participation activity increase in other events within process of mixed learning.

About need of training teachers to new education is written in the research of Ntuli and Kyei-Blankson (2016). The article tells about necessity to train future pedagogues to effective use of Internet resources for teaching children. For this purpose, researchers propose to improve tasks on practice and include educational course on the use of Internet technologies. In this article, the experience in solving of this matter has been very interesting. In our research, here is also shown the problem of pedagogues' unpreparedness to apply educational websites in process of teaching mathematics.

Analyses of educational institutions' websites accessibility and suggestions of the ways to improve the design of educational institutions' web pages are conducted in the research of Kesswani and Kumar (2016). The authors note that preparation of accessible sites was not earlier so much important as today. Due to the increase in accessibility and compliance with accessibility standards, more researches on this issue appear nowadays. The paper has analyzed the availability of websites at higher educational institutions in different countries. Besides, the authors propose recommendations aimed to improve the design of web pages of educational institutions. The issue of websites availability is of interest for our research in terms of limiting websites application. Many websites allow access to a specific range of users. The terms can be as follows: registration on the website, membership in the educational institution, payment for the content. The experience of websites openness and accessibility is compelling for the research. The interactive educational platform UCHI.ru has a limit for users (learners) of 20 tasks per day after 16.00. On the one hand, this fact can be viewed positively - children are not overloaded with additional tasks; on the other hand, it can have some negative results - there are children for whom 20 tasks are not enough to develop some mathematical skills.

The study on the ease and effectiveness of websites application, in particular the Morpa Campus website, was carried out by Çetin and Özdemir (2013). The researchers tried to find out if the learner can effectively use the Morpa Campus website to perform basic and complex tasks during navigation on course topics. The experiment was aimed to identify the convenience of the site and not results of tasks performance. Participants are children aged between 9-11 years. The following encompasses main criteria to understand children's demand in website: efficiency, satisfaction and ease of application. The research showed that this site is very popular with learners, but there are some problems with usability. It was found out that technical difficulties caused problems in using the web-site: problems with the Internet connection, long waiting time for server's response, low speed of information transferring.

Evaluation of educational websites for parents who have children with attention deficit disorder and hyperactivity is shown by Ryan, Haroon, and Melvin (2015). Researchers note that getting of actual and correct information about this disorder has great importance, especially in account of widespread delusions. The authors tried to find out the influence of such websites on parents' views and get links for optimization of users' experience.

One of the advantages in teaching with the help of websites is possibility to provide individual learning route for students. In the research of Dogan and Dikbiyik (2016), the work of adaptive web teaching intellectual system named OPCOMITS is shown. There is used conceptual model of mapping for themes regulation hierarchy, for evaluation of student's knowledge about theme and for stimulation of learning. Thus researchers propose adaptive and effective educational environment that evaluates student's knowledge according to theme, enhances inverse relationship, diagnoses blank in knowledge and suggests the ways of work out.

Experimental research was performed by Chodos et al. (2014); they developed a model to describe student's actions in a simulator of virtual world. The Avatar capabilities model is used as a basis for building medical students' activity. Simulation considers student's actions (studying of movement, experience of impact on objects and social interactions). Such modeling is important for assessing students' practical activities through imitation.

Also there attains interest the research of Sylaiou et al. (2017) about teaching with the help of virtual world. The researchers write about teaching with the use of virtual museums. This article helps to understand educational influence of virtual models. The process that is suggested by authors for achieving educational result is based on the specifics of introducing complex $3 \mathrm{~d}$ constructions.

Researchers Sinyak and Tarasevich (2014) investigated the role of the website in scientific and educational activities. The article proves the urgency to develop the site at the department of production management and real estate economy at Belarusian State Technological University. Main characteristics of the site, requirements for it and tasks of its use in the educational process are specified. Additional information services of the site aimed at openness and increase of education quality are being discussed. This article provides the circle of users of the site; and in accordance with users' requests, it offers a form for developing information structure of the website. In the framework of our research, the convenience of interactive educational platform interface for work of children aged $8-9$ years is considered. 
Works of Russian scientists aimed at studying Web sites application are of concern. Thus, Griban and Griban (2015) conducted the research to describe professional self-actualization applying web sites. The authors assume that educational websites as components of the Internet space play a special role in educators' professional activity in modern conditions. The paper presents the typology of educational websites for self-realization; they allow to create a socially useful product in professional activity to promote the recognition of the employee's work and achievements. As for our research, the very process of organizing training with the help of a website is useful. We believe that if mixed instruction is applied, then there is need to create and place teaching materials for teachers or parents on the same website. The lack of methodological materials on the use of educational websites leads to an incorrect definition of their didactic role in the educational process.

\section{MATERIALS AND METHODS}

\section{Experimental Base and Methods of Research}

The research was conducted in the city of Kazan, the Republic of Tatarstan, the Russian Federation; it had three stages of the experiment: stating, forming and control.

Questionnaire-diagnostic methods (questioning, testing) to reveal the dynamics of mathematical skills formation were employed in the process of UCHI.ru interactive educational platform application.

We verified the ability:

- to use properties of arithmetic operations for the convenience of calculations;

- to solve problems in many ways, to build a mathematical model of the problem;

- to calculate a perimeter and / or an area of non-standard geometric figure;

- to compare values (length, weight);

- to interpret information obtained in a simple research.

Two controls were implemented: at the beginning of the research (the stating stage) and at the end (the control stage). Learners solved test tasks in mathematics in hard copy within one academic hour.

Second grade school students aged between 8-9 years took part in the research. The total number of students participating in the research made 311 people; 12 teachers were recruited as well. The study was conducted from December 12, 2016 to April 28, 2017.

All teachers in these grades have the highest qualification category. The final control in the subject "Mathematics" for the previous academic year in the experimental and control groups showed almost the same academic performance.

Group number 1 (for observation) includes grades that have already been working with the interactive educational platform UCHI.ru since the age of 7. Group 2 (control group) is made of grades that do not work with the interactive educational platform UCHI.ru. Group number 3 (experimental) embodies grades that included tasks of UCHI.ru interactive educational platform into their training and extra-curricular activities at the forming stage of the experiment.

\section{Characteristics of UCHI.ru Interactive Educational Platform}

The methodology of our study is the educational website UCHI.ru (https://uchi.ru/). This website is an interactive educational platform.

The description of the interactive educational platform UCHI.ru.

This platform has been designed to teach school subjects to school students in all regions of Russia (Figure 1).

At the moment, the platform has registered: 100,000 teachers, more than 1500,000 students, 800,000 parents, 20,000 schools in Russia. Professional methodologists have created an interactive course in mathematics for primary school on the platform; it contains interactive assignments on primary school topics. This course was integrated into the process of primary schoolchildren teaching. 


\section{5 thousand school children of 1st-4th grade from every region of Russia}

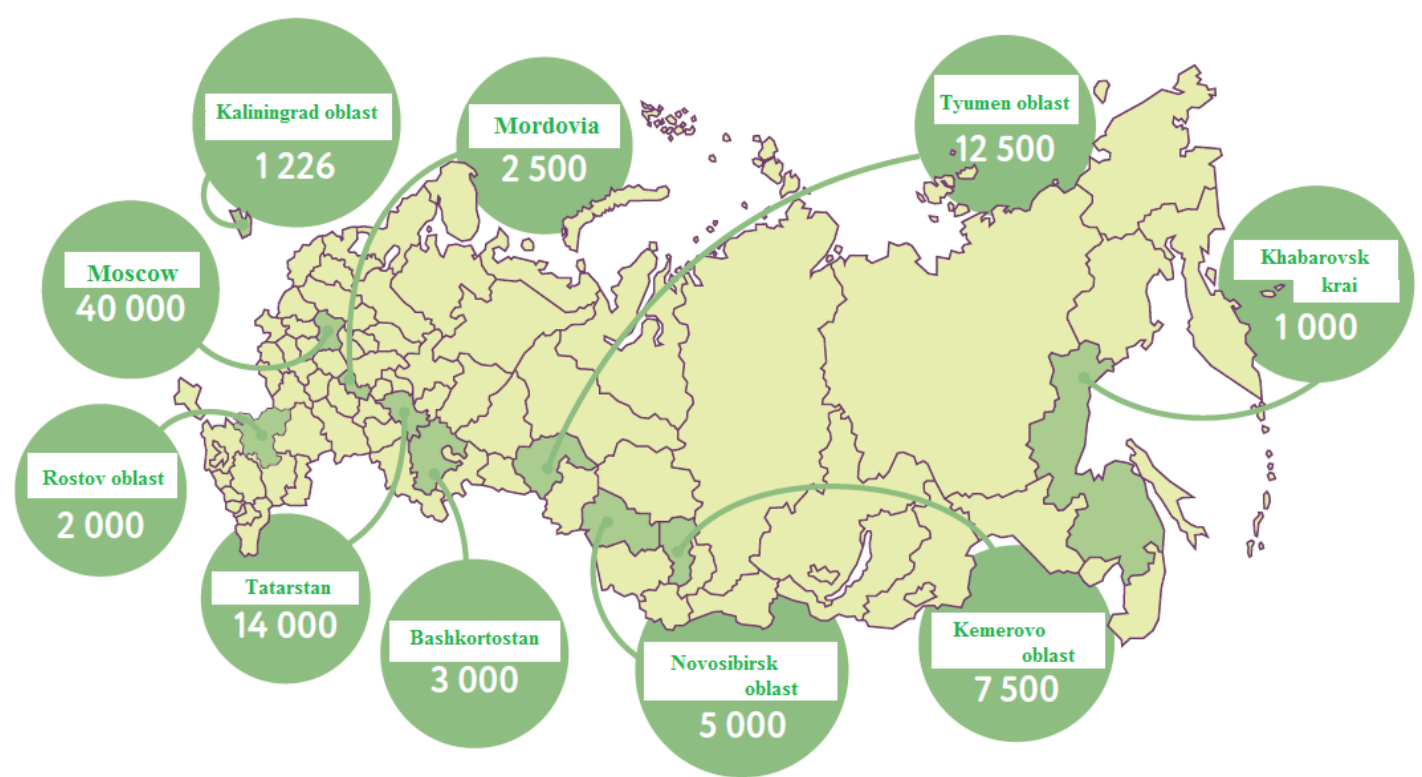

Figure 1. The number and geography of registered users in Russia

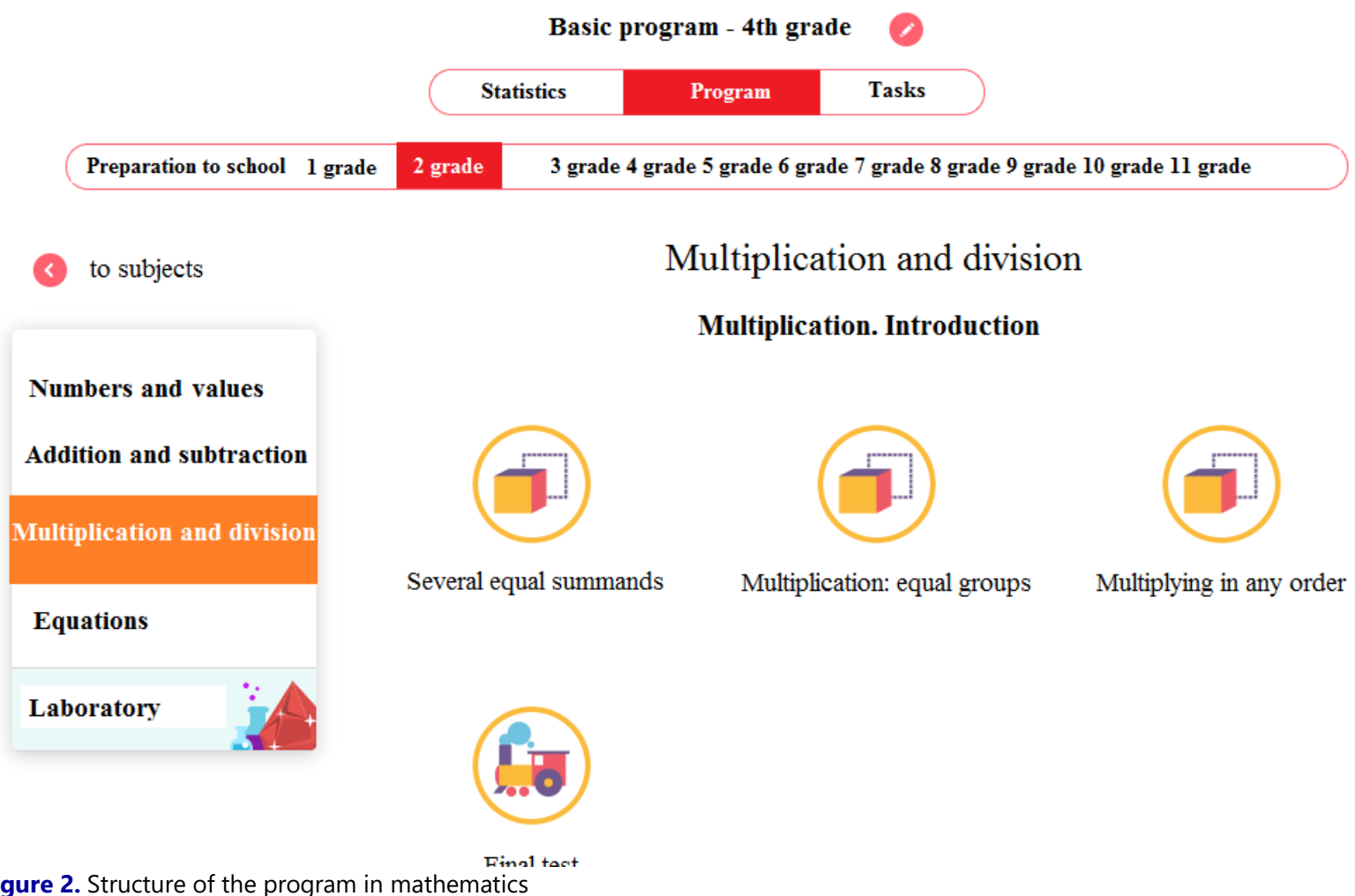

Figure 2. Structure of the program in mathematics

The description of the interactive course in mathematics on the UCHI.ru platform.

The course includes interactive assignments for pupils of 1-4th grades. The material is divided in compliance with prime school curriculum (Figure 2). Each class contains a program that reflects sections of "Mathematics" as the academic subject; each section has topics, and each topic is divided into several lessons. Lessons consist of interactive tasks; assignments are aimed to test mathematical skills. 
Divide 10 crystals and put them into boxes, so that each box should have 5 crystals.

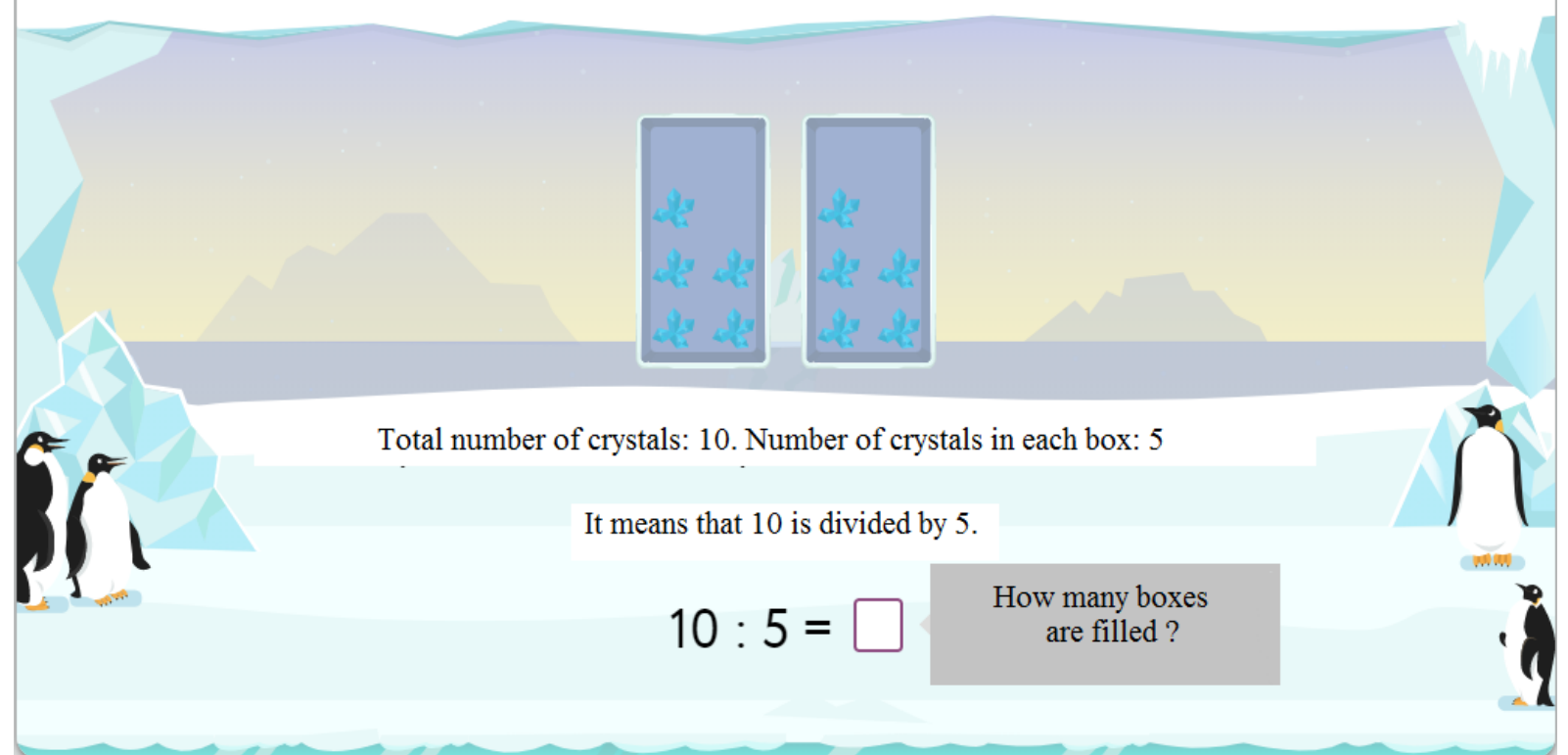

Figure 3. The interactive characteristics of the UCHI.ru platform work

The platform works in the interactive regime (Figure 3): the system asks the child a question and reacts to the given answer; in case of correct decision, it praises the student and suggests a new task; in the event of an error, it asks clarifying questions to help the student to come to the right decision; besides it selects the level of complexity.

The algorithm of work using the interactive course in mathematics on the UCHI.ru platform.

Second grade students were recruited for the research. Table 1 shows how the plan for teaching mathematics was created. 
Table 1. Thematic plan for teaching mathematics

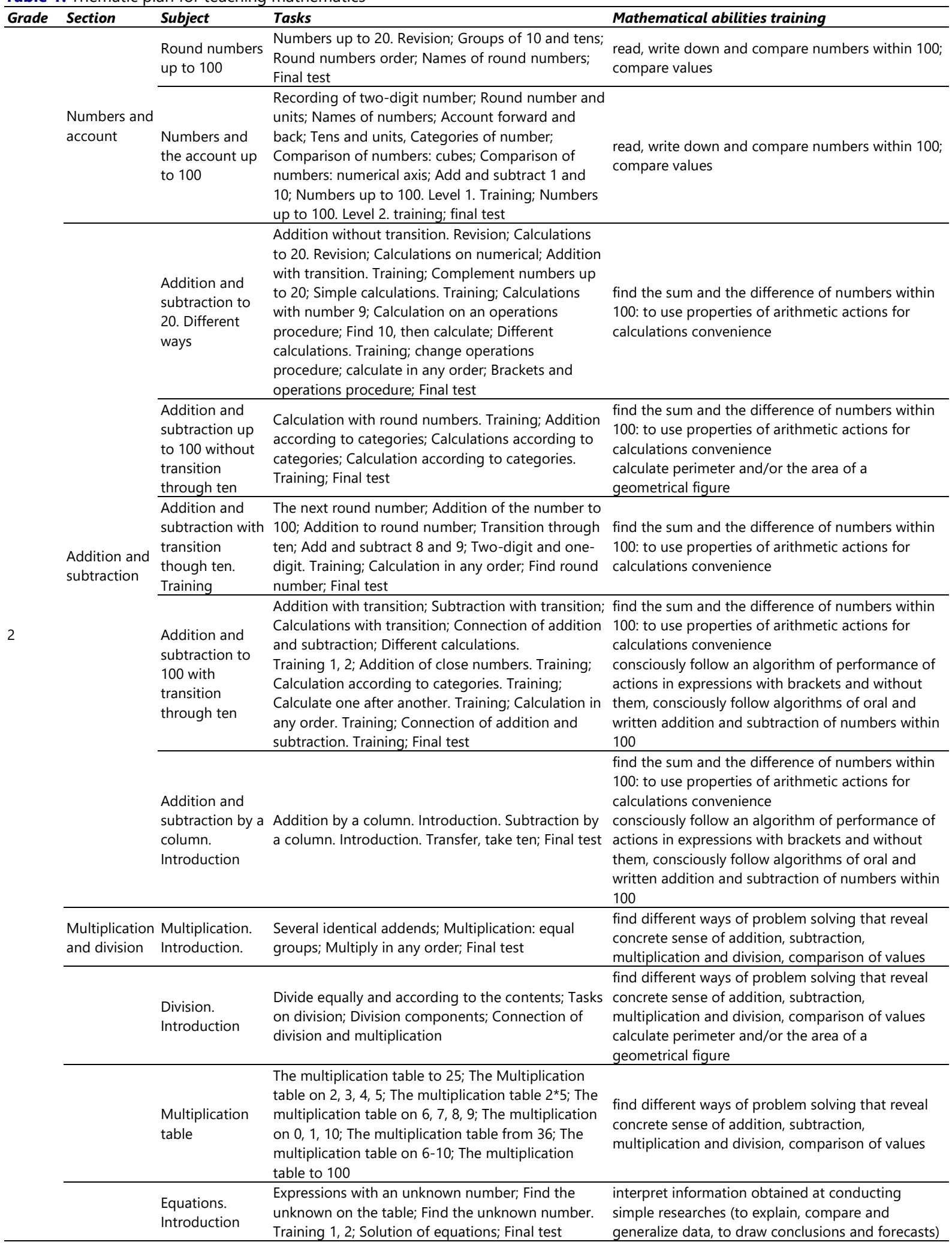

School students performed 92 tasks at math classes in total. The program of an interactive course of mathematics is supplemented with the section "Laboratory" in which problems of different level of complexity (Figure 4) are included. Tasks were performed as extra-curricular activities; the teacher advised school students if they faced difficulty. 


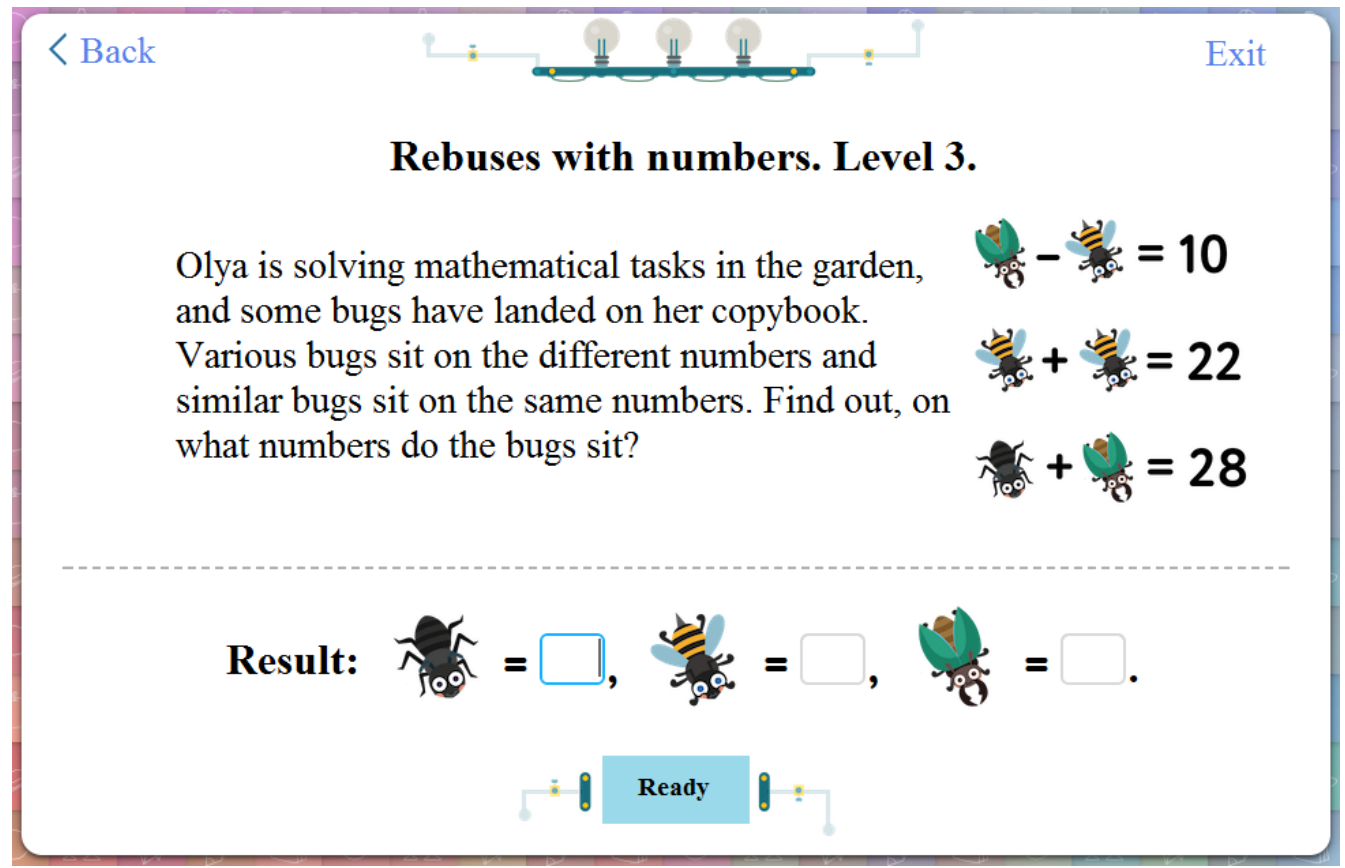

Figure 4. Example of the task (3 level) from the section "Laboratory"

to subjects

Mathematics 2nd grade

Basic program

Statistics Program Tasks

Basic program - 2nd grade

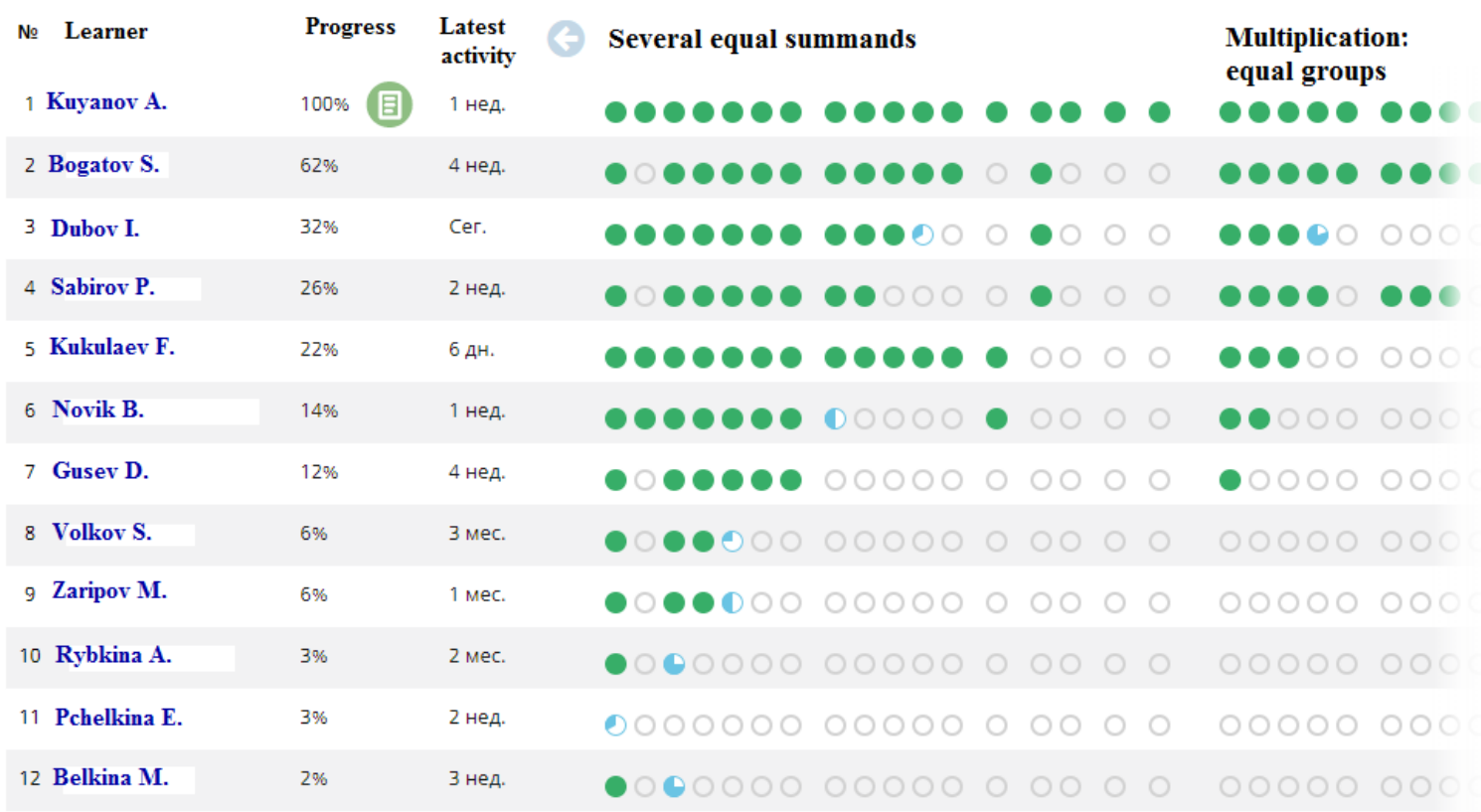

Figure 5. Statistics of students' work on the subject

The interactive educational platform allows the teacher to receive comparative statistics of progress for each specific student and the whole class, in general. The teacher sees in statistics what subject the school student is working on, how many tasks are performed correctly and how many of them are incorrect, and the percent of all correctly performed tasks (Figure 5). 
Through the statistics teacher sees the activity of the child. The latest activity is shown in the table. For successful learning of basic program learner gets diploma.

\section{RESULTS}

\section{The Stating Experiment}

Before work on the interactive educational platform UCHI.ru, second grade students were given tests aimed to reveal the formation of their mathematical skills:

- the first task identified skills for using arithmetic properties for the convenience of calculations;

- the second task identified the ability to find different ways to solve the problem. School students had to write down a mathematical model of solving problem;

- the third task was aimed to calculate the perimeter and area of a non-standard geometric figure;

- 4 task identified the ability to compare values;

- the 5th task required to interpret the information obtained by the way of simple research (explain, compare and generalize data).

The results of the stating stage (the percentage of successfully performed tasks) (Figures 6-8): in the experimental group $-46.2 \%$, in the control group - $46.6 \%$, in the group for observation $-77.8 \%$.

1,2 and 5 tasks caused a greater number of difficulties.

Children should find the value of a mathematical expression in the first task. They had to perform four arithmetic operations: addition, subtraction, multiplication and division. Children in the experimental and control groups had errors in calculations since such arithmetic operations as multiplication and division had been explained to them not long before.

As for the 2nd task, it was difficult for children to build a mathematical model of the problem, though the problem was solved. The group for observation implemented the second task very well. But the experimental and control groups showed a low percentage of implementation.

The 5th task was supposed to solve an unusual task that required reasoning. Children from all three groups made mistakes.

Let us note that in the 4th task aimed to compare values (length, weight), children distinguish homogeneous values; however, they make mistakes when it comes to express some units with the help of others. There were more mistakes in the experimental and control groups.

\section{The Forming Research Phase}

This stage provided the development of mathematical abilities in primary school students by means of the interactive educational UCHI.ru platform. The department of preschool and primary education of IPE KFU and methodologists of the UCHI.ru company arranged integrated training for teachers of the third group according to the program "Use of the interactive environment "Mathematics. UCHI.ru" at primary school". The program was designated to perfect primary school teachers' professional competences in teaching "Mathematician" applying the interactive educational UCHI.ru platform. The training course considered principles of building and structure of the interactive course "Mathematics", methodical features of studying some topics in Mathematics with the use of the interactive UCHI.ru platform, psychological and pedagogical features of primary school students trained by means of educational platforms. The round-table discussions, that followed the training, considered approaches to tasks performance of the interactive educational UCHI.ru platform in class and extracurricular activities. Thus, teachers of this group were trained for the research.

Teachers of the $3 \mathrm{~d}$ group held parents' meetings in their grades from February 3-10, 2017. Differentiated extracurricular work on the fulfillment of supplementary tasks (at school students' requests) on the interactive educational platform UCHI.ru was regarded.

The forming stage was conducted from January 16 to April 14, 2017. The $3 \mathrm{~d}$ group of students and their teachers were engaged in this work.

In the forming stage, the teachers elaborated technological maps of forthcoming lessons, and tasks of the interactive educational platform UCHI.ru were integrated into the content of these lessons. Technological maps of lessons were created in compliance with thematic planning of lessons according to the educational and methodical complex "School of Russia": 2nd grade, topics: "Written technique of addition of the type 45 + 23", "Subtraction of the type 52 - 24", "Specific meaning of multiplication", "The commutative property of multiplication", 


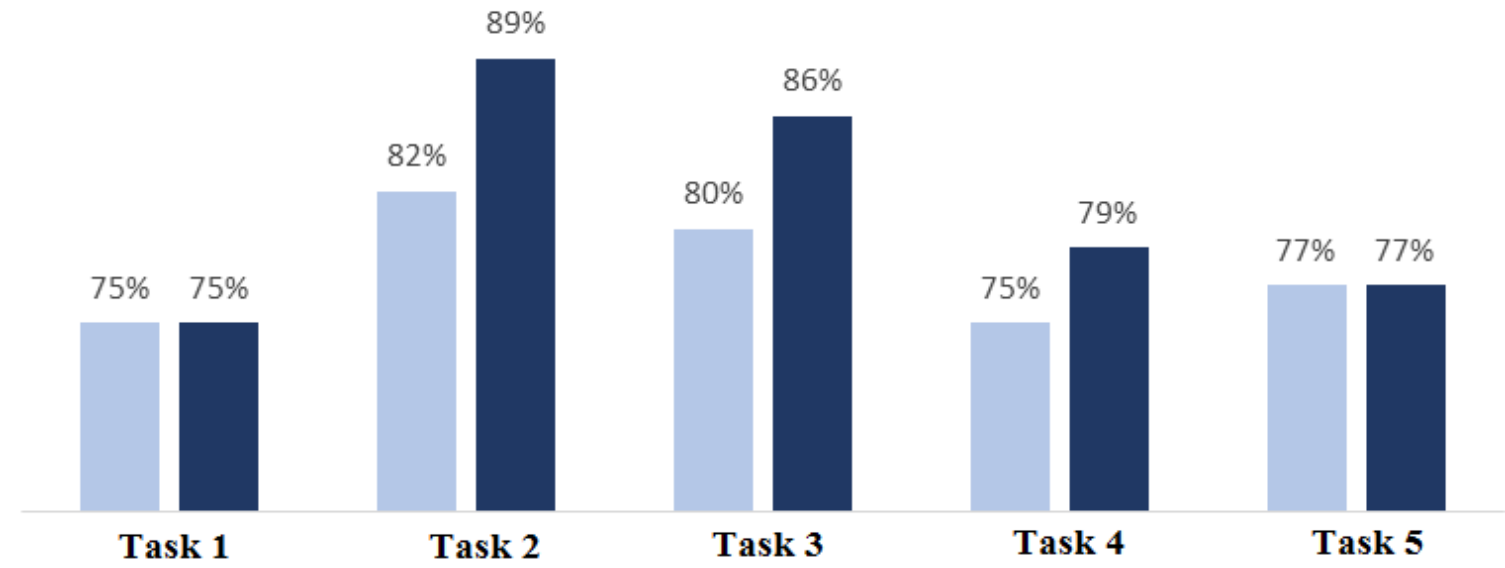

Figure 6. Percentage of school students performed tasks (group 1)

Input testing

- Output testing

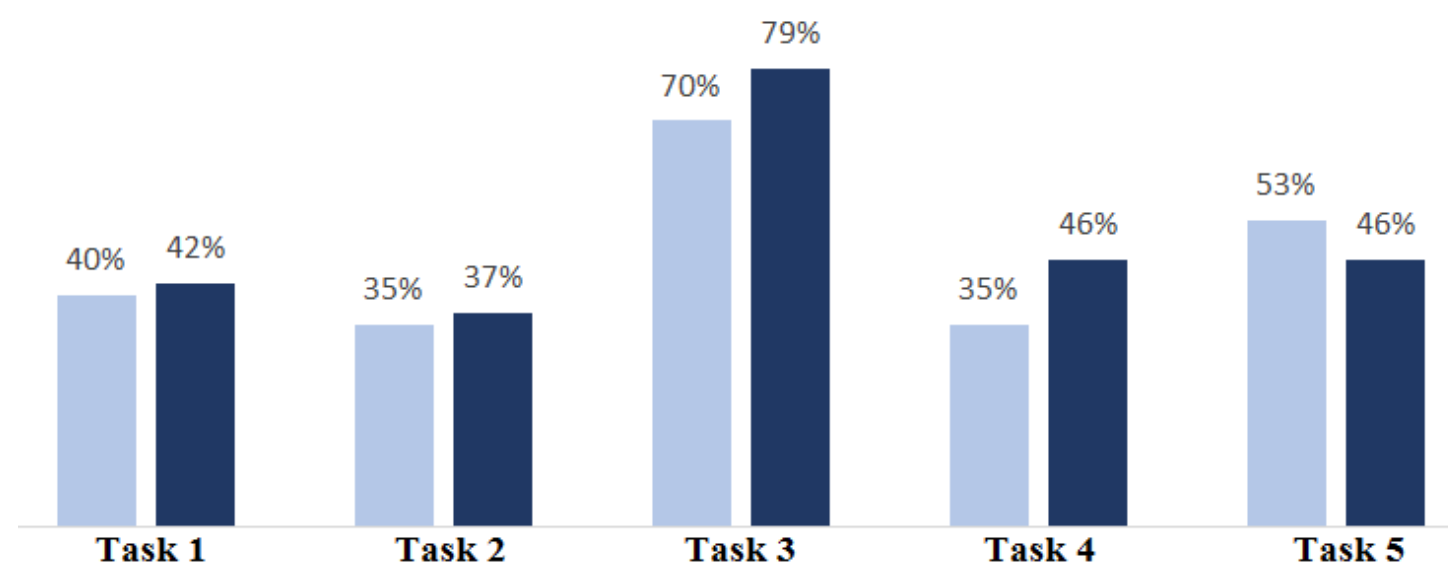

Figure 7. Percentage of school students performed tasks (group 2)

"Multiplication and division of numbers". Besides, extra-curricular lessons were held to solve non-standard tasks using the educational interactive platform UCHI.ru.

The forming stage of the research resulted in discussions. It was noted that school students' educational motivation was improved. Children willingly performed interactive tasks, showed interest, discussed solutions and tried to solve non-standard tasks on the platform UCHI.ru.

\section{The Control Stage}

Re-diagnosis was elaborated on the basis of two variants of tests for each grade in the same way as it was done for the stating stage of the research: 5 tasks in compliance with the educational program "School of Russia". Diagrams below specify the results of children's test tasks performance in the stating and control stages.

Results of the control stage (percentage of successful task performance) (Figures 6-8): in the experimental group $-68.4 \%$, in the control group - $50 \%$, in the group for observation $-81.2 \%$.

The average success rate of tasks performance in the 2 nd grade in the experimental group increased by $22.2 \%$ compared to the control group with $3.4 \%$. At the same time, group 1 which studied on the UCHI.ru platform before and during the research (forming stage of the research), showed steadily high results in the stating and control stages of the research, respectively. It should be noted that children in group 1 have been studying with the use of the interactive educational platform UCHI.ru since the age of 7. 
Input testing

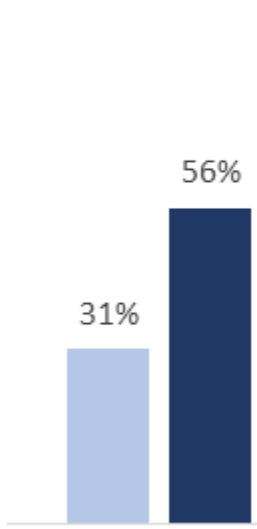

Task 1

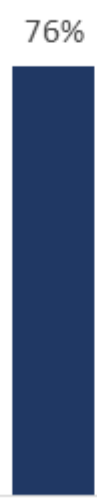

Task 2
- Output testing

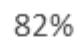

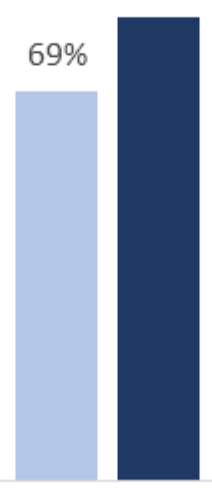

Task 3

Figure 8. Percentage of school students performed tasks (group 3)

Group No. 1 (for observation) showed steadily good results in our research.

Group No. 2 (control group) displayed average results, which slightly increased by the end of the research, but not in the 5 th task.

Group No. 3 (experimental group). Scores in the stating and control stages significantly differ. At the end of the research children showed high achievements on all tasks.

\section{DISCUSSION}

The development of information and communication technologies changes the process of training. We can't help considering modern realities. Modern educated people face quite different requirements. Children should be taught to study using information space (Ivanova \& Osmolovskaya, 2011).

Interactive educational platforms are an integral part of modern primary school. Each student has an opportunity to build his/her educational route as such educational activity is variable and multilevel and helps achieve actual results (Chernobay, 2012).

However, the analysis of questioning (56 respondents) conducted among teachers and parents made it possible to determine problem areas in training mathematics with the use of the interactive educational UCHI.ru platform. Problem areas are revealed in two aspects:

content level

- the order in which topics are arranged on the website does not always correspond to the program of training in mathematics for a concrete class;

- there are not enough tasks on comparison of values (length, weight, time, area, volume, cost, speed).

- there are no methodical recommendations (instructions) for teachers and parents on class and extracurricular activities arrangement with the use of websites;

- there are no interesting mathematical facts, there is no information on great mathematicians;

technological level

- the child is registered more often as a part of a class; when transferred to another school he/she loses all achievements;

- teachers' private office results of work are reflected on the website of all students in class, however children themselves "do not see" leaders in training;

- the main character is not interactive;

- the mobile version is not quite optimized;

- the possibility to work per day is limited for users (20 tasks after 16:00). 


\section{CONCLUSION}

The conducted research specified that supplementary interactive tasks of UCHI.ru interactive educational platform efficiently impact the formation of mathematical abilities:

- to use properties of arithmetic actions for the convenience of calculations;

- to solve problems applying different ways, ability to build a mathematical model of the task;

- to calculate perimeter and/or area of a nonstandard geometrical figure;

- to compare values (length, weight);

- to interpret information obtained after conducting simple researches in primary school students.

At the end of the research, children of the experimental group showed high achievements in mathematical tasks performance in comparison with the control group where UCHI.ru interactive educational platform was not applied.

In our opinion, UCHI.ru interactive educational platform is helpful for teaching mathematics to 8-9-year-old children as this platform implies the following opportunities:

1. to promote mathematical knowledge and mathematical education;

2. to increase students' motivation due to strengthening of interactive nature of training and intensification of students' educational activity;

3. to provide an individual educational route of primary school students: to eliminate gaps in basic knowledge for each student, to overcome individual difficulties; to provide children having high motivation and outstanding mathematical abilities with appropriate conditions for development.

We note positive dynamics of UCHI.ru interactive educational platform impact on educational achievements of each child - the participant of the research, regardless his/her original level of mathematical abilities formation.

UCHI.ru interactive educational platform can be recommended as supplementary didactic material in training mathematics.

\section{ACKNOWLEDGEMENT}

The work is performed according to the Russian Government Program of Competitive Growth of Kazan Federal University.

The work is done with the use of interactive educational platform UCHI.ru developed by specialists of UCHI.ru.

\section{REFERENCES}

Castaño-Muñoz, J., Duart, J. M., \& Sancho-Vinuesa T. (2014). The Internet in face-to-face higher education: Can interactive learning improve academic achievement? British Journal of Educational Technology, 45(1), 149-159. https:/ / doi.org/10.1111/bjet.12007

Çetin, E., \& Özdemir, S. (2013). A Study on an Educational Website's Usability. Procedia - Social and Behavioral Sciences, 83, 683-688. https://doi.org/10.1016/j.sbspro.2013.06.129

Chernobay, E. V. (2012). Technology of lesson preparation in modern informational and educational environment. Moscow: Prosvechenie.

Chodos, D., Stroulia, E., King, S., \& Carbonaro, M. (2014). A framework for monitoring instructional environments in a virtual world. British Journal of Educational Technology, 45(1), 24-35. https://doi.org/10.1111/j.14678535.2012.01370.x

Dmitrieva, N. V., Zaitseva, N. A., Kulyamina, O. S., Larionova, A. A., \& Surova, S. A. (2015). Scientific and theoretical aspects of the staff recruitment organization within the concept of "Talent Management". Asian Social Science, 11(3), 358-365. https:/ / doi.org/10.5539/ass.v11n3p358

Dogan, B., \& Dikbiyik, E. (2016). OPCOMITS: Developing an adaptive and intelligent web based educational system based on concept map model: An educational system based on concept map model. Computer Applications in Engineering Education, 24(5), 676-691. https:/ / doi.org/10.1002/cae.21740

Faleeva, L. V., Bratukhina, E. V., Ezhov, S. G., Gorbunova, L. N., Lopanova, A. P., Viaznikova, L. F., \& Kryukova, N. I. (2017). Student's social experience forming in university vocational training. Eurasian Journal of Analytical Chemistry, 12(7), 1127-1135. https:/ / doi.org/10.12973/ ejac.2017.00238a 
Filatov, V. V., Zaitseva, N. A., Larionova, A. A., Zhenzhebir, V. N., Polozhentseva, I. V., Takhumova, O. V., \& Kolosova, G. M. (2018). State Management of Plastic Production Based on the Implementation of UN Decisions on Environmental Protection. Ekoloji, 106, 635-642.

Firsova, I., Vasbieva, D., Prokopyev, A. I., Zykin, E. S., \& Matvienko, V. V. (2018). Development of consumers' behavior business model on energy market. International Journal of Energy Economics and Policy, 8(4), 227-233.

Galushkin, A. (2015). Internet in modern Russia: History of development, place and role. Asian Social Science, 11(18), 305-310. https:// doi.org/10.5539/ass.v11n18p305

Griban, O. N., \& Griban, I. V. (2015). Educational web sites as the mean of pedagogues' self-realization. Pedagogical education in Russia. Federal state budget educational institution of higher professional education "The Ural state pedagogical university", 41-44.

Ivanova, E. O., \& Osmolovskaya, I. M. (2011). Theory of teaching in informational society. Moscow: Prosvechenie.

Kalugina, O. A., \& Tarasevich, N. A. (2018). Smart technology integration into EFL teaching at the non-linguistic higher school. XLinguae, 11(1XL), 8-18. https:/ / doi.org/10.18355/XL.2018.11.01XL.02

Kesswani, N., \& Kumar S. (2016). Accessibility analysis of websites of educational institutions. Perspectives in Science, 8, 210-212. https://doi.org/10.1016/j.pisc.2016.04.031

Kvon, G. M., Lushchik, I. V., Karpenko, M. A., Zaitseva, N. A., Kulkov, A. A., Galushkin, A. A., \& Yakupova, N. M. (2017). Regional investment policy: analysis and assessment of the investment environment state. Eurasian Journal of Analytical Chemistry, 12(5), 835-853. https:/ / doi.org/10.12973/ ejac.2017.00215a

Kvon, G. M., Prokopyev, A. I., Shestak, V. A., Ivanova, S. A., \& Vodenko, K. V. (2018). Energy saving projects as energy security factors. International Journal of Energy Economics and Policy, 8(6), 155-160.

Lubimova, E. M., \& Sabanaev, I. A. (2014). Development of higher education students' abilities in independent work on the base of web technologies by means of merging into professional activity. Modern problems of science and education, 4, 463-474.

Lubnina, A. A., Shinkevich, M. V., Ashmarina, S. I., Zaitseva, N. A., Saifutdinova, G. B., \& Ishmuradova, I. I. (2016). Resource saving innovative forms of the industrial enterprises. International Journal of Economics and Financial Issues, 6(2), 479-483.

Ntuli, E., \& Kyei-Blankson, L. (2016). Improving K-12 Online Learning: Information Literacy Skills for Teacher Candidates. International Journal of Information and Communication Technology Education, 12(3), 38-50. https:/ / doi.org/10.4018/IJICTE.2016070104

Oborsky, A. Y., Chistyakov, A. A., Prokopyev, A. I., Nikolyukin, S. V., Chistyakov, K. A., \& Tararina, L. I. (2018). The national mentality in the history of philosophy. XLinguae, 11(3), 158-165. https:/ / doi.org/10.18355/XL.2018.11.03.15

Petrovskaya, M. V., Zaitseva, N. A., Bondarchuk, N. V., Grigorieva, E. M., \& Vasilieva, L. S. (2016). Scientific methodological basis of the risk management implementation for companies capital structure optimization. IEJME - Mathematics Education, 11(7), 2571-2580.

Pyankova, N. G., \& Matviyuk, V. M. (2014). Influence of global network Internet on psychic of teenagers. Concept, 30, 246-252. Retrieved on February 20, 2018, from http:/ / e-koncept.ru/2014/14858.htm

Rudenko, L., Zaitseva, N., Larionova, A., Chudnovskiy, A., \& Vinogradova, M. (2015). Socio - economic role of service - sector small business in sustainable development of the Russian economy. European Research Studies Journal, 18(3), 223-238.

Ryan, G. S., Haroon, M., \& Melvin, G. (2015). Evaluation of an educational website for parents of children with ADHD. International Journal of Medical Informatics, 84(11), 974-981. https:// doi.org/10.1016/j.ijmedinf.2015.07.008

Sabirova, E. G., \& Zakirova, V. G. (2016). Formation of mathematical terminology in junior school children. Mathematics Education, 11, 1787-1795.

Scanlon, E. (2014). Scholarship in the digital age: Open educational resources, publication and public engagement. British Journal of Educational Technology, 1, 12-23. https:/ / doi.org/10.1111/bjet.12010

Shcherbakov, V. S., Makarov, A. L., Buldakova, N. V., Butenko, T. P., Fedorova, L. V., Galoyan, A. R., \& Kryukova, N. I. (2017). Development of higher education students' creative abilities in learning and research activity. Eurasian Journal of Analytical Chemistry, 12(5), 765-778. https:/ / doi.org/10.12973/ ejac.2017.00209a

Sinyak, N. G., \& Tarasevich, B. O. (2014). Role of web site in scientific and educational activity. Higher technical education. Byelorussian state technological university, 8, 142-144. 
Sylaiou, S., Mania, K., Paliokas, I., Pujol-Tost, L., Killintzis, V., \& Liarokapis F. (2017). Exploring the educational impact of diverse technologies in online Virtual Museums. International Journal of Arts and Technology, 10(1), 58-84. https:/ / doi.org/10.1504/IJART.2017.10004738

Vasbieva, D. G., Sokolova, N. L., Masalimova, A. R., Shinkaruk, V. M., \& Kiva-Khamzina, Y. L. (2018). Exploring the EFL teacher's role in a smart learning environment - a review study. XLinguae, 11(2), 265-274. https:/ / doi.org/10.18355/XL.2018.11.02.21

Wang, F. H. (2017). An exploration of online behaviour engagement and achievement in flipped classroom supported by learning management system. Computers $\mathcal{E}$ Education, 114, 79-91. https:// doi.org/10.1016/j.compedu.2017.06.012

Zaitseva, N. A., Larionova, A. A., Filatov, V. V., Rodina, E. E., Zhenzhebir, V. N., Povorina, E. V., \& Palastina, I. P. (2018). Natural-Resource Potential Management of Region's Territorial Ecosystems Issue. Ekoloji, 106, 495502.

Zaitseva, N. A., Larionova, A. A., Gornostaeva, Zh. V., Malinina, O. Yu., Povalayeva, V. A., Vasenev, S. L., Skrynnikova, I. A., \& Ersozlu, A. (2017). Elaboration of the methodology for assessing the development of managerial competences in university students taught with the use of case-technologies. Eurasia Journal of Mathematics, Science and Technology Education, 13(11), 7339-7351. https:// doi.org/10.12973/ ejmste/79609

\section{http://www.ejmste.com}

